\title{
Reflections on the Impact of $\mathrm{K} \& \mathrm{~S}$ as a Systematic Textbook
}

\author{
Thom Verhave \\ Queens College, CUNY
}

We celebrate and honor two marvellous teachers, whose impact on our lives as psychologists as well as persons has been enormous. It was Fred as well as Nat who encouraged me to become not only an experimental psychologist but a historian of experimental psychology as well. I honor them in that dual function.

My title is as dry as Arizona's desert sand.... It was, however, exactly the systematic nature of $\mathrm{K} \& \mathrm{~S}$ that turned on so many undergraduates at Columbia College, myself included. There are many other reasons why we celebrate the book's imminent 40th anniversary, but the effectiveness of Fred Keller's lectures can not possibly have been one of them. He denounced lectures on the basis of a sound psychological principle in $K$ \& $S$ itself. He then went on to invent The Personalized System of Instruction (PSI) to get out of the business of throwing his verbal pearls before incomprehending swine (Keller, 1982). The sound principle Fred appealed to for his rejection of the "Lecture Method" is as old as it is important. Here it is straight from our mentor's pages:

The lecture method provides no reinforcement for the hearer's speech except the long-delayed one of examination and final grade. It is not to be wondered that, with the small comprehension achieved by lectures, students often aim on examinations only to reproduce verbatim the lecturer's words. . . . [it] inherently promises little for any but selected audiences already so well trained in a special subject matter that the heard words fit into, and generalize with, a verbal repertory prepared in advance and primed at high strength while listening. (p. 398)

This "Principle of Assimilation" was familiar to 19 th century psychologists and

Preparation of this manuscript was supported in part by NIH Grant RO1-HD2-11 10 to Lanny Fields, College of Staten Island, CUNY and Thom Verhave, Queens College, CUNY. Reprints may be requested from the author at the Department of Psychology, Queens College, CUNY, Flushing, NY 11367. educators through the influence of J. F. Herbart (1776-1841) and the Herbartians (Dunkel, 1969, 1970; Herbart, 1897). New information, to be comprehended, must be "integrated," "assimilated," "made to fit," or "restructured" with knowledge already mastered. That, in brief, was at the core of the concept of Apperception from Herbart through Wundt (Danziger, 1987; Lange, 1894). It is restated over and over again by various authors of different systematic persuasions (Haslerud, 1972; Ogden, 1914; Piaget, 1926) and lies again at the very core of the Human Information Processing approach of Lindsay's and Norman's systematic cognitive textbook of 1977. PSI will, no doubt, soon be reinvented as a form of cognitive engineering.

How is it possible for so basic a principle to be "rediscovered" over and over again? The answer, in brief, is that there is an inherently negative side to any systematic conceptual approach. On the one hand, a systematic approach makes for greater clarity and comprehension with respect to the materials it includes. On the other hand, it induces "conceptual blinders" for whatever it excludes. A way of being taught to "see things," is also a way of learning "not to see" other things (Burke, 1954). In addition, social mechanisms come into play: Prejudice against others with a different systematic orientation develops quickly among competing groups. The consequences for the progress of psychology as an experimental science have been devastating. Experimentalists of different systematic persuasions, such as Gestaltists, Hullians, Tolmanians, Skinnerians, Lashleyans, and Cognitivists of various stripes, have fought nasty battles with each other, and ignored or denigrated each other's contributions. United and historically better informed, they could have stood their ground against the criticisms of non-ex- 
perimentalists. Divided, experimentalists have given undue weight to the criticisms of logicians, linguists, and philosophers who frequently have been ignorant of the historical accumulation of replicable experimental data and the steady improvements in the research methods that made gathering these data possible. In science, method is the bottom line. Let all data and theories be wiped out, as long as the knowledge of the methods by which they were obtained would be preserved, everything else could be rediscovered and reinvented (Nietzsche, 1878 in Kaufman, 1954, pp. 63-64). I will return to this theme again.

In what does the "systematicity" of $\mathrm{K}$ \& $S$ consist? Not just in its implementation of the old and well established didactic rule of gently ascending from simple to more complex curricular material, a corollary of Herbart's principle of assimilation. What attracted me as a student was the interplay between its conceptual organization and the proof of general conclusions by way of replicable experimental data with single subjects. In addition there was the book's insistent appeal to experimental method as fundamental, and its explicit rejection of authority. As Richard M. Elliott put it succinctly in his Editor's Introduction "the basis of every science lies not in talk and proof by say-so, but in experimental methods" (p. v). That was an appealing message to me, a rebellious young man whose experiences in Europe from 1940 through 1948 had left him with little trust and respect for the "talk and say-so" by the adults of those bitter days. Finally, there was the promise that something important was happening, that psychology need not, like philosophy, remain an endless debating society in which no issues and arguments could ever be resolved. Perhaps, just perhaps, psychology might be able to join the ranks of the more mature empirical sciences such as physics, chemistry, physiology and genetics. Perhaps the world would change for the better after all. Why then not join "the thinking and research of [this] active group of psychologists in this country. The members of [which] were mainly ex- perimentalists, laboratory workers ... unflaggingly on the lookout for fundamental principles of behavior" (Keller \& Schoenfeld, 1950, p. vii). Why not accept so heady an invitation to join so important an adventure in the New World. And so I did, and became an experimental psychologist and an American citizen.

\section{SYSTEMATIC PREDECESSORS}

The system or organization Keller and Schoenfeld imposed on their psychological curriculum was, of course, largely drawn from Skinner's Behavior of Organisms (1938). It is for this reason that $K$ \& $S$ could write in their preface that they

had felt, for some time, the need for a book that would integrate classical and contemporary thought in a way that would adequately represent the dominant theoretical trend of today. But when, at last, we undertook to write it ourselves, we soon became aware of the difficulties involved. We had no models to work from, no tradition to follow, at the undergraduate level of exposition. With respect to the content as well as the form of our text, we had to rely upon our own judgement, again and againoften with misgivings. (pp. vii-viii)

$\mathrm{K}$ \& $\mathrm{S}$ cite three earlier behavioristic textbooks in their bibliography: J. B. Watson's Psychology from the Standpoint of a Behaviorist of 1919, Karl F. Muenzinger's Psychology: The Science of Behavior (1942) and the third edition of 1949 of J. F. Dashiell's Fundamentals of General Psychology. The title of Dashiell's first edition of 1928 is significantly different: Fundamentals of Objective Psychology. That same year also saw the publication of another "objective" textbook: Human Behavior by Walter Hunter (1928) whose graduate seminar Fred and Fred were to attend at Harvard in 1929. It was "a natural outgrowth of my General Psychology" (1919), wrote Hunter (1928, p. v).

Why did K \& S not use these and other earlier behavioristic textbooks for guidance (Cole, 1939; Smith \& Guthrie, 1929; Starch, Stanton, \& Koerth, 1936)? There are two ready answers: 1 . these books, like Watson's of 1919 and Dashiell's and Hunter's of 1928 were too old and out- 
dated; 2 . they were irrelevant since they were uninformed by the discoveries and the systematic point of view of Skinner's Behavior of Organisms or "Reinforcement Theory" in general (Keller, 1954). The second answer must be qualified somewhat since the expressed aim of the $\mathrm{K}$ \& S text was to "integrate classical and contemporary thought" (p. vii). That was also the aim of Cole's book (1939) and Dashiell's three editions of 1928, 1937 and 1949. Wrote Dashiell in the preface to the second edition:

New fields of research have led to mines of new factual material. New facts, in their turn, have demanded strikingly new and fruitful characterizations and interpretations.... All these and other yeasts have been leavening the loaf. What the immature student and thoughtless layman realize all too little is that, like newer concepts in physics or any other field of science, each advance does not destroy the older view but amplifies it. $(1937$, p. v)

And so Dashiell, like $\mathrm{K} \& \mathrm{~S}$, incorporated experimental data from far and wide. Wrote K \& S: “Our systematic position has not kept us from looking at facts in other theoretical contexts. Good data are good data, regardless of theory" (p. 14). So I may add is good experimental methodology.

What then is the special contribution $K \& S$ made to the education of myself as an experimentalist and historian? They-like Dashiell-taught their readers to be objective and to look for good data regardless of its source. Thus they encouraged me to start digging into the historical background of psychology. In addition, they have imparted the classical experimental methodological tradition of the 19th century physiologist to new generations of experimental psychologists in the "rat laboratory." It is here exactly that $K \& S$, in contrast to Dashiell, have, in my opinion, made their most important and lasting contribution. Systematic positions come and go as structuralists, behaviorists, psycholinguists, and cognitivists have all found out to their chagrin during the last four decades (Baars, 1986). The methodology of single subject experimentation, however, has flourished since the days of Fechner, Donders, Wundt, Ebbinghaus, Pavlov,
Skinner, and $K$ \& $S$. Today it is ready to tackle the so-called higher mental processes of human subjects without the many pitfalls of ANOVA. Improved experimental methods lead to better data, and better data lead in turn to better grounded "systematic positions" without a Deus ex Machina like Chomsky's "Language Acquisition Device" (Verhave, 1972).

As I asserted above, much damage has been done by the exclusivity and isolation of different groups of experimental psychologists. The existence of two different divisions of experimentalists in a now moribund APA has been a scandal and a calamity. Behaviorists, since the days of John B. Watson, have also been isolated and alienated from each other, much to their own detriment. Dashiell was too optimistic when he wrote in 1928 that only "the immature student and thoughtless layman" do not appreciate that in science, "each advance does not destroy the older view but amplifies it" (p. v). Experimental psychologists have been their own worst enemies.

This is not the occasion to give a detailed comparison of the order in which behavioristic textbooks such as $K$ \& $S$ and Dashiell's lay out their curriculum. But whether you turn to Watson's, Dashiell's, or K \& S's, they all wind up with an analysis of language, the traditional "window on the mind" since Descartes. It was the behaviorists' analysis of language, of course, which was found to be flawed by any number of critics. Just what was the contribution of J. B. Watson and other behaviorists to that analysis?

Let me selectively track the analysis of how a "language habit" such as the proper use of the word "orange," is learned by infants starting with Watson's textbook of 1919. These discussions, by the very nature of a general term like "orange," also present the first discussions of the development of Naming as well as Equivalence classes, a topic which has currently become a hot area of research among members of this society. How "naming" develops is also a hot topic among cognitively oriented psychologists (Macnamara, 1982; Nelson, 1985). 


\section{J. B. WATSON AS A \\ PIONEER DEVELOPMENTAL PSYCHOLOGIST}

Let's start then with John B. Watson's 1919 description of the development of "language habits" as he called them. Watson has hardly had a fair press among psychologists since he was dismissed from Johns Hopkins University because of a divorce scandal. Much has been said and written about him that merely shows either the lack of any acquaintance with what in fact he wrote or dwells on alleged less pleasant sides of his character. His extensive research with children has been a well kept secret (Watson, 1917). I will let Watson himself set the record straight by presenting his account of the development of verbal behavior in children. An entire chapter (IX) is devoted to The Genesis and Retention of Explicit and Implicit Language Habits. The Introduction makes the, supposedly obvious, point that "man is a social being and [that] almost from birth language activity becomes a part of his every adjustment even though that adjustment be made to other than a social situation" (p. 310). It was not obvious in 1919, and Nelson (1985, 1986) still feels obliged to argue the case for social context in her important work on the acquisition of shared (verbal) meaning in children. Watson's stress on the "environment" was part of a broader intellectual movement away from the hereditarianism of the 19th century for which all traits, physical and phrenological, were due to "bad seed" or "good stock" (Fowler, 1843, 1847; Galton, $1883,1869)$. That broader movement also included a stress on social or cultural factors, as represented by Franz Boas, Gabriel Tarde, George Herbert Mead, John Dewey, A. P. Weiss, L. S. Vygotsky, and Wilhelm Wundt's Völkerpsychologie. The notion of authors, whose historical knowledge is non-existent, that Watson's environmentalism somehow derives from John Locke's "blank slate" (Small, 1990, p. 14) is pure mythology as are so many other psychologists' notions of "the origins of behaviorism," radical or otherwise.
Watson's brief introduction concludes by saying that "the subject of ... language processes ... is so vast and can be approached from so many angles and points of view that we can give only an extremely meagre account of its main features" $(1919$, p. 310). The next section describes The Anatomical Basis of Language, the larynx and The Production of Laryngeal Sounds and, though it is of interest, need not be discussed here (cf. Dashiell, 1928). It is the next section on The Formation of Language Habits that provides the "baseline discussion" which subsequent "objective" experimentalists and theoretical thinkers such as Meyer, Weiss, and Dashiell, expanded so as to constitute the first phase in the development of an objective analysis of verbal and symbolic behavior.

There are two subsections in Watsons's discussion: A. deals with The Formation of Explicit Language Habits, B. with The Formation of Implicit Language Habits. I will say nothing about Watson's historically important analysis of the factors which change explicit into covert speech (cf. Dashiell, 1928; Skinner, 1957). It deserves a separate article. The discussion of Explicit Language Habits has four parts:

1. Early Reflex and Instinctive Responses.

2. Early Vocal Habits.

3. Early Language Habits.

4. Rapidity of Formation of Language Habits.

Section 1 begins with a discussion of the "purely observational study" of the "early sounds in infants," quoting from a "Mrs. Blanton" without citing a reference. Watson had written his book in a hurry (Pauly, 1986).

In 1917 M. G. Blanton had published a paper on The behavior of the human infant during the first thirty days of life. Subsequent publications by Blanton, in what had become an active area of research since 1920, are listed in Dorothea McCarthy's extensive survey of 1954 in the Manual of Child Psychology which also lists the articles by Drever (1915/ 1916) and Bateman (1914) which were the sources Watson used to present a 
graph dealing with "the speed of word habit formation" to be discussed later.

Investigators interested in early language development had long realized the importance and necessity of descriptive data which would constitute an inventory of the initial vocal repertory of young infants (McCarthy, 1954). Watson lamented the fact that "no very satisfactory laboratory study has yet been made of the ... vastly complex ... early instinctive vocal equipment of the infant" (p. 317) and makes some suggestions for further research. As Dashiell points out in the last edition (1949) of his text,

In America the use of strict scientific methods in the observation of the human infant and child may be said to have begun about 1910. In a psychological laboratory attached to the maternity award of the Johns Hopkins Hospital, Watson and his colleagues had the opportunity of studying newborn subjects in experimentally controlled ways. (1949, p. 66)

By 1917, Watson and his collaborators had "had several hundreds of newborn infants under observation" (Watson, 1917, p. 57).

\section{VOCAL VERSUS LANGUAGE HABITS}

Watson (1919) begins by drawing a distinction between "early vocal habits" and "language habits" which though learned, are a "mere sounding of words of the non-instinctive type" (p. 318). They have not "yet been connected up with other vocal action and with general bodily actions" (p. 318). A similar distinction between "proto-language" or "pre-linguistic vocalizations" and "pre-lexical" or "non-symbolic" language forms is still prevalent in the current literature (Nelson, 1985 , p. 80 ). To Watson such early "vocal word habits" are formed in much the same way as are other explicit habits, an important and still controversial statement that was to be repeated by Dashiell in all three editions of his textbook (1928-1949) and upheld again by Skinner (1957). According to Watson, only "one additional factor" seems to come in which plays a special role in the "fixing" of these "vocal word habits" as contrasted with "the acquisition of manual habits": imitation. "In the laboratory," wrote Watson, "we have tried many times to get children from ten to eighteen months to imitate simple movements, like putting the hand flat upon the table, putting the two hands together, but without much success" (p. 318). With proper procedures, such "generalized imitation" has been demonstrated recently by Poulson and Kymissis (1988). Watson's failure here-he should have used the infant's parents as models -is less important than the fact that he pioneered such studies and not Guillaume (1926). In the case of "vocal acts" however, "imitation seems to be a process directly connected with the establishment of the act" (p. 319). Even so, Watson argued against its importance for reasons that need not concern us here (see pp. $259 \& 318-319$ ).

\section{EARLY LANGUAGE HABITS}

\section{Wrote Watson (1919):}

Vocal acts or habits ... do not become language habits until they become associated with arm, hand and leg activities and substitutable for them. This probably accounts in a better way than any hypothetical change in brain structure for the relatively late putting on of language habits. As long as the child remains in its crib, ... or has the whole household to wait upon and anticipate its needs, there is no necessity for it to develop language. If we examine the bodily habits of any child just prior to the beginning of true language habits, we find that it can respond appropriately to hundreds of objects and situations, for example, to its doll, bottle, blocks, rattle and many other things. Its environment is becoming complex. Abbreviated and short-circuited actions become a necessity if it is to hold its own in that environment and make progress. (p. 319)

Watson's (1919) account of how "word meaning" develops goes as follows: Assume a child is looking for a favorite toy which happens to utter the sound "tata" rather frequently.

The attendant ... predicts that an old rag doll is sought. She finds it, hands it to him and says, "Here's your tata." Repeat this process long enough and "tata" will be always used for rag doll and will always be spoken whenever the doll is sought. (p. 320)

Thus, “. . . repeated again and again ... the word gets tied up with the act of seeking the doll" (p. 320). It is "in this way 
[that] baby words grow up as the first genuine form of true language organization" (p. 320). "The putting on of conventional speech habits is thus an illustration of conditioned reflex level of functioning [vocal habit] plus later associative connection of the word when learned with the object for which the word stands (true language habits)" (p. 320). For Watson then, the development of "true language habits" does not involve the mere conditioning of "vocal" reflexes; it involves, in addition, subsequent "associations" which turn words into symbols. In this latter process, words, as they are used by either children or the adults around them, are connected with the "bodily habits" which are in turn connected with the objects that have conventional "names." Thus in a more detailed illustration of this process, Watson describes how a child may initially come to hear the spoken words and phrases such as "box," "open box," "close box," and "put blocks in box" in the social context of interacting with "a nurse" as, at the same time, it executes appropriate finger and hand movements. Once such "conditioned reflexes" are "thoroughly established," the toy box "which originally called out only bodily habits, now begins to call out word habits. He says 'box' when it is handed to him, 'open box' when he opens it"' (p. 320). Thus the box can now elicit either a "manual" or "laryngeal" action.

It is at this point that the influence of the environment upon the shaping and forcing of language habits comes clearly to the front. There comes an occasion when the box can be seen but not reached... He speaks "box".... The attendant, hearing the word box, hastens to put it in his hands. (p. 321)

Thus comes about "a substitution of the language habit for a bodily habit." In Walter Hunter's $(1919,1928)$ terms two "functionally equivalent responses" have been established, something very different from a class of equivalent stimuli, of course. In Skinner's (1957) terms, the child has learned to "tact" as well as "mand" a toy box. "This roughly marks," writes Watson (1919) with the characteristic caution of a researcher, "what we might call the genesis of a true language habit. It is a very inadequate account, but we are forced to be content with it until the process has been studied more carefully in the laboratory" (p. 321). Watson ends this subsection by pointing out that the learning processes involved in the development of simple language habits are the same as those involved in the development of any other habits. Language acquisition is social only in that "the child is surrounded by individuals who use conventional word forms" and thus provide "the auditory and visual stimuli which lead to such habit formation" (p. 321).

Section 4, on the Rapidity of Formation of Language Habits, presents an early graphic presentation of the growth of children's vocabulary of words as a function of age. It is based on data collected by two investigators, J. Drever (1915/16) and W. G. Bateman (1914). The figure "gives a rough indication of the speed of word habit formation" (pp. 321-322). Children's "vocabularies increase with astonishing rapidity" (p. 322), Watson (1919) comments, a phenomenon that George Miller and Noam Chomsky were to make much hay with. Plots of similar data can be found in many textbooks since 1919 and again in Katherine Nelson's 1985 book. The data, in spite of ambiguities about observer criteria for the occurrence of a "word," are quite consistent across investigators and raise the fundamental question about the "generativity" of symbolic behavior (cf. Haslerud, 1972; Osgood, 1953).

Watson's discussions of language $(1914,1919)$ influenced subsequent behavioristic investigators such as Max Meyer and his student, A. P. Weiss (Esper, 1968, 1973; Myer, 1921). Weiss builds on Watson as well as Meyer, and I will turn to his analysis next.

I will only bring out what is most novel: an analysis of naming words as equivalence classes in a discussion of The Generalizing Function of Language. The source is The Theoretical Basis of Human Behavior (1925), a work dedicated to Max F. Meyer. Wrote Weiss:

Because the word response is independent of the sensory nature of the stimulus, many different stim- 
uli may release the same word reaction. This form of behavior is known as generalization, and the process may be described as the generalizing function of language. As a behavior category generalization is a type of sensory-motor mechanism in which many different receptor patterns representative of many different sensory situations and relations, are connected to the same language response and through this common path the individual may react in a specific manner to all the objects and situations, and relations thus connected, even though there is very little sensory similarity between them [italics added]. (p. 297)

\section{By way of illustration, Weiss discussed}

the generalized language response of the word food When the word apple was being taught as the reaction to the sight of an apple, handling reactions such as peeling, eating, hiding, cooking, were also acquired. At a later time in the addition to the name apple another name was taught, that of the word food; for the object bread the child acquired the name bread but also such handling reactions as toasting, soaking in milk ... and again the name food which is also one of the names of the apple;... . The verbal response food is thus a common sensorymotor mechanism which connects the objects apple, bread, milk, with their respective handling reactions of peeling, slicing, boiling, drinking, etc., much more directly than with each other. (1925, pp. 297-298)

Earlier, in his discussion of how a child learns the name orange, Weiss, like Watson before him, pointed out that this typically takes place in specific social situations such as the "breakfast situation" [italics added]. Here, "certain elements of this situation are constant from day to day, - the sight of the parents, the table appointments, the time of day, etc. The child's verbal orange reaction (along with many others) becomes part of the breakfast situation" (1925, p. 294). The above analysis has recently been restated by Katherine Nelson in the metaphorical terminology of "scripts," "slots," and "event representations" (Nelson, 1985, 1986, 1988; Small, 1990).

Weiss (1925) sums up his discussion as follows:

The speech mechanism that produces the word food thus serves two purposes: (1) The sound of the word food may act as a stimulus to prepare the individual to react by any of the food handling reactions of peeling, slicing, . . . , etc., when a given class of nonsimilar sensory stimuli (foods) are presented. (2) The sight of any new object which resembles the edible food objects but for which the individual has not learned a specific handling reaction, may release the reaction food and this in turn the repertory of food handling sensory-motor mechanisms so that the new handling reaction which is formed may be developed from those responses which require least modification and which already represent the biologically most adequate responses. ... Simply stated the generalizing function of language organizes the whole repertory of reactions which the individual possesses into groups and sub-groups which are made available through appropriate language stimuli, without the need of the stimuli of the actual objects or situations. This makes possible an almost unlimited refinement of behavior categories. ... [And] an artificial set of stimuli (words) may release responses that are entirely dissimilar from the original sensory learning conditions. (pp. 298-299)

Elsewhere in his book, Weiss referred to the results of such learning processes as the formation of "biosocial equivalences" (1925, pp. 47 \& 49; cf. Dashiell, 1937 , p. vi).

To sum up, Weiss recognized two important "mechanisms" in which speech is prominently implicated: (1) the formation of biosocial equivalence classes and (2) the transfer and generation of new "handling reactions" to new objects which resemble stimuli which are already members of an equivalence class.

Let me now briefly return to the three recurring themes of this talk: (a) experimental psychologists have been their own worst enemies, (b) the importance of adequate experimental methodology, and (c) the impact of $K \& S$ on their students at Columbia and elsewhere.

First consider that among "behaviorists" of various stripes, Equivalence Classes and their importance have been discovered at least three times, by A. P. Weiss in the twenties, by J. J. Jenkins during the sixties (Baars, 1986) and by Murray Sidman in the seventies (Sidman, 1971). As far as Jenkins is concerned, suffice it to say that his conception of the formation of an equivalence class was less sophisticated than that of Weiss and that his research program failed due to inadequate methodology. We cheerfully credit Murray Sidman with the initiation of the latest revival of equivalence class research with a more adequate single subject methodology. As far as cognitive psychologists are concerned, they have been under the illusion that a shift in jargon or just dreaming up new 
metaphors would automatically correct the presumed faults of their behaviorist past (Miller, 1974). So they have dismissed whatever sound data and methodology was to be found in the behavioristic literature. Thus can one of the more promising and theoretically oriented developmental psychologists such as Katherine Nelson, who is interested in how children develop word meanings in social settings, be ignorant or unaware of the contributions of Watson, Weiss, Skinner, Sidman, etc.

I referred earlier to the work of Watson, Weiss, and Dashiell as the first phase in the history of the behavioristic assault on the "Higher Mental Processes." The second phase, represented by Cofer and Foley (1942), Fred Keller's study of the effect of the "Phonetic Equivalent" in Morse Code training (Keller, Christo, \& Schoenfeld, 1946), Osgood (1953), Skinner's Verbal Behavior (1957) and the K \& $S$ text, has in my opinion come to an end. The current research represents a new phase for several reasons. Single subject methodology is being transformed by the microcomputer revolution. We can do things now that were inconceivable 10 years ago. Once effective software to gather and analyze data has been written it becomes essentially public domain once the research has been published. This means that anyone can now do single subject research with human subjects and will do so if it is indeed a better way of doing things. I recommend we give our software away to any other experimentalist who wants to use it. Equally important are the improvements in the experimental methodology used in current equivalence research. Our own software is an implementation of Fred Keller's PSI, but dedicated to the effective formation of equivalence classes for research purposes.

\section{WHAT WILL THE FUTURE BRING?}

As behavior analysts we may well be on our way to solve two problems that have plagued experimental psychologists since Ebbinghaus did his pioneering research more than a hundred years ago.
Both problems are explicitly mentioned by Donahoe and Palmer (1989).

They point out that Skinner's analysis of verbal behavior represents an interpretation of complex behavior by pursuing "the implications of experimental-analytic principles ... using the conventions of ordinary language" (p. 403). Furthermore what distinguishes such interpretation "from mere speculation is that ... it appeals only to processes that have been identified in prior experimental analyses" (p. 403). It has been the "prior experimental analysis" that throughout the first and second phase has been lacking or inadequate and thus left the interpretation open to criticism. A better experimental analysis of such cognitive processes as induction and concept formation or categorization will make interpretation either unnecessary or better grounded (Lee, 1988).

They also point out that most human experimentation is also a form of interpretation.

This is so because ... the processes contributing to complex behavior are not all under the control of the experimenter. Although [such] research ... may carefully control the variables within the experiment, the differing preexperimental selection histories of the subjects outside the study cannot be completely controlled or even described. (p. 403)

Better experimental methodology may well be about to solve that problem too by neutralizing a subject's prior history or by tapping into it in a controlled way. When that happens the old "Principle of Assimilation" and the "Problem of Transfer" (Haslerud, 1972; Woodworth, 1938) will have been operationalized and will have been transformed into a set of experimentally proven regularities or "laws."

There are also signs that the mutual isolation of the warring camps of experimentalists may be coming to an end. The fruitless battles of "Systems" and "Philosophies" will be a thing of the immature past.

We celebrate on this occasion the role of two great teachers and their contribution to our education. Nietzsche, referring to Schopenhauer, wrote that one honors one's teacher by going beyond him 
(Nietsche, 1874). Science does this as a matter of course. The experimental analysis of behavior has only just begun (Lee, 1988).

\section{REFERENCES}

Baars, B. J. (1986). The cognitive revolution in psychology. New York: Guilford Press.

Bateman, W. G. (1914). A child's progress in speech. Journal of Educational Psychology, 5, 307-320.

Blanton, M. G. (1917). Behavior of the human infant during the first thirty days of life. Psychological Review, 24, 513-540.

Burke, K. (1954). Permanence and change. Indianapolis: Bobbs-Merrill.

Cofer, C. N., \& Foley, J. P. (1942). Mediated generalization and the interpretation of verbal behavior: I. Prolegomena. Psychological Review, 49, 513-540.

Cole, L. E. (1939). General psychology. New York: McGraw-Hill.

Danziger, K. (1987). Apperception. In R. L. Gregory (Ed.), The Oxford companion to the mind (pp. 33-34). New York: Oxford University Press.

Dashiell, J. F. (1928). Fundamentals of objective psychology. Boston: Houghton Mifflin.

Dashiell, J. F. (1937). Fundamentals of general psychology. Boston: Houghton Mifflin.

Dashiell, J. F. (1949). Fundamentals of general psychology. Boston: Houghton Mifflin.

Donahoe, J. W., \& Palmer, D. C. (1989). The interpretation of complex human behavior: Some reaction to Parallel Distributed Processing, edited by J. L. McClelland, D. E. Rummelhart, and the PDP research group. Journal of the Experimental Analysis of Behavior, 51, 399-416.

Drever, J. (1915/1916). A study of children's vocabularies: I, II, \& III. Journal of Experimental Pedagogy, 3, 34-43; 96-103; 182-188.

Dunkel, H. B. (1969). Herbart and education. New York: Random House.

Dunkel, H. B. (1970). Herbart and Herbartianism. Chicago: University of Chicago Press.

Esper, E. A. (1968). Mentalism and objectivism in linguistics. New York: Elsevier.

Esper, E. A. (1973). Analogy and association in linguistics and psychology. Athens: The University of Georgia Press.

Fowler, O. S. (1843). Hereditary descent: Its laws and facts applied to human improvement with hints to women; including directions for forming matrimonial alliances so as to produce, in offspring, whatever physical, mental, or moral qualities may be desired; together with preventives of hereditary tendencies. American Phrenological Journal, 5, Nos. 9, 10, 11, \& 12.

Fowler, O. S. (1847). Hereditary descent: Its laws and facts applied to human improvement. New York: Fowler's \& Wells.

Galton, F. (1869). Hereditary genius: An inquiry into its laws and consequences (2nd ed.). New York: Horizon Press.
Galton, F. (1883). Inquiries into human faculty and its development (3rd ed.). London: Dent.

Guillaume, P. (1926). L'Imitation chez l'enfant. Paris: Alcan.

Haslerud, G. M. (1972). Transfer, memory, \& creativity. Minneapolis: University of Minnesota Press.

Herbart, J. F. (1834/1897). A textbook in psychology. New York: Appleton.

Hunter, W. S. (1919). General psychology. Chicago: University of Chicago Press.

Hunter, W. S. (1928). Human behavior. Chicago: University of Chicago Press.

Kaufman, W. (1954). The portable Nietzsche. New York: Viking Press.

Keller, F. S. (1954). Learning: Reinforcement theory. New York: Random House.

Keller, F. S. (1982). Pedagogue's progress. Lawrence, KS: TRI Publications.

Keller, F. S., Christo, I. J., \& Schoenfeld, W. N. (1946). Studies in International Morse Code: V. The effect of the "phonetic equivalent." Journal of Applied Psychology, 30, 265-270.

Keller, F. S., \& Schoenfeld, W. N. (1950). Principles of psychology. New York: Appleton-Century-Crofts.

Lange, K. (1894). Apperception. A monograph on psychology and pedagogy. Boston: Heath.

Lee, V. L. (1988). Beyond behaviorism. Hillsdale, NJ: Erlbaum.

Lindsay, P. H., \& Norman, D. A. (1977). Human information processing. New York: Academic Press.

Macnamara, J. (1982). Names for things. Cambridge: MIT Press.

McCarthy, D. (1954). Language development in children. In L. Carmichael (Ed.), Manual of child psychology (pp. 492-640). New York: Wiley.

Miller, G. A. (1974). Toward a third metaphor for psycholinguistics. In W. Weimer \& D. Palermo (Eds.), Cognition and the symbolic process (pp. 397-413). Hillsdale, NJ: Erlbaum.

Muenzinger, K. (1942). Psychology: The science of behavior. New York: Harper.

Myer, M. F. (1921). Psychology of the other-one. Columbus: The Missouri Book Company.

Nelson, K. (1985). Making sense: The acquisition of shared meaning. New York: Academic Press.

Nelson, K. (1986). Event knowledge: Structure and function in development. Hillsdale, NJ: Erlbaum.

Nelson, K. (1988). Where do taxonomic categories come from? Human Development, 31, 310.

Nietzsche, F. (1874/1965). Schopenhauer as educator. Chicago: Regnery.

Ogden, R. M. (1914). An introduction to general psychology. New York: Longmans, Green.

Osgood, C. E. (1953). Method and theory in experimental psychology. New York: Oxford University Press.

Pauly, P. J. (1986). G. Stanley Hall and his successors: A history of the first half-century of psychology at Johns Hopkins. In S. H. Hulse \& B. F. Green (Eds.), One hundred years of psychological research in America (pp. 21-51). Baltimore: Johns Hopkins. 
Piaget, J. (1926). La répresentation du monde chez l'enfant. Paris: Alcan.

Poulson, C. L., \& Kymissis, E. (1988). Generalized imitation in infants. Journal of Experimental Child Psychology, 46, 324-336.

Sidman, M. (1971). Reading and auditory-visual equivalences. Journal of Speech and Hearing Research, 14, 5-13.

Skinner, B. F. (1938). The behavior of organisms. New York: Appleton-Century-Crofts.

Skinner, B. F. (1957). Verbal behavior. New York: Appleton-Century-Crofts.

Small, M. Y. (1990). Cognitive development. New York: Harcourt, Brace, Jovanovich.

Smith, S., \& Guthrie, G. (1929). General psychology in terms of behavior. New York: Appleton.

Starch, D., Stanton, H. M., \& Koerth, W. (1936). Controlling human behavior. New York: Macmillan.
Verhave, T. (1972). The language and mind of a polemicist: Some reflections on Language and Mind by Noam Chomsky. Journal of Psycholinguistic Research, 1, 183-195.

Watson, J. B. (1914). Behavior: An introduction to comparative psychology. New York: Holt.

Watson, J. B. (1917). Practical and theoretical problems in instincts and habits. In $\mathbf{H}$. B. Jennings, J. B. Watson, A. Meyer, \& W. I. Thomas (Eds.), Suggestions of modern science concerning education (pp. 51-99). New York: Macmillan.

Watson, J. B. (1919). Psychology from the standpoint of a behaviorist. Philadelphia: Lippincott.

Weiss, A. P. (1925). The theoretical basis of human behavior. Columbus, OH: R. G. Adam.

Woodworth, R. S. (1938). Experimental psychology. New York: Holt. 